Proc. 13th Econophysics Colloquium (EC) and 9th Symposium of Physics in Economy and Social Sciences (FENS), 2017

\title{
Impact of the Secondary Insider Trading on Financial Markets
}

\author{
A. JAKImowicz ${ }^{a, *}$, A.A. BAKLARZ ${ }^{b}$ AND K. SMUlskA ${ }^{c}$ \\ ${ }^{a}$ Institute for Market, Consumption and Business Cycles Research - National Research Institute, \\ Al. Jerozolimskie 87, PL-02001 Warsaw, Poland \\ ${ }^{b}$ Faculty of Management, University of Warsaw, Szturmowa 1/3, PL-02678 Warsaw, Poland \\ ${ }^{c}$ WSB University, Młodzieżowa 31A, PL-87100 Toruń, Poland
}

\begin{abstract}
The insider trading phenomenon is based on the situation when traders use material information not publicly available to make their investment decisions. In most countries of the world, insider trading is illegal and is punishable by fine or imprisonment. Insider trading has many economic effects, which in the light of available scientific research can be both positive and negative. Insider traders can be divided into primary and secondary traders depending on whether their contact with insider information is direct or indirect. Primary insider trading has been discussed in many research studies and scientific descriptions, while secondary insider trading has not been investigated yet. This paper's aim is to fill this gap. Since the empirical data for secondary insider trading is in practice impossible to obtain, the research analysis is based on simulations of two probabilistic models. The first one concerns the use of insider information for an infinite long period of time after its acquisition, while the second one on the day of its receipt. The results of the simulation are related to three basic models of financial market functioning: the efficient market hypothesis, the fractal market hypothesis, and the coherent market hypothesis.
\end{abstract}

DOI: 10.12693 /APhysPolA.133.1394

PACS/topics: 89.65.Gh, 02.70.-c

\section{Introduction}

Insider trading and fraud are considered to be main violations of the symmetry of information on the financial markets. Insider trading is therefore regulated by law in many countries. For example, Regulation (EU) No $596 / 2014$ of the European Parliament and of the Council gives a precise definition of inside information and explains the use of it [1]. In general, confidential information is accurate information for issuers or certain financial instruments that have not been disclosed to the public. Its disclosure would probably have a significant impact on prices (Article 7(1)). Moreover, "insider dealing arises where a person possesses inside information and uses that information by acquiring or disposing of, for its own account or for the account of a third party, directly or indirectly, financial instruments to which that information relates. The use of inside information by cancelling or amending an order concerning a financial instrument to which the information relates where the order was placed before the person concerned possessed the inside information, shall also be considered to be insider dealing" (Article 8(1)). This regulation also lists two types of entities for which it is forbidden to make transactions insider trading. The first one is related to the company whose shares can be bought or sold on the stock market (for instance: managers, employees, and etc.). On the other hand, it might be "any person who possesses inside information $(. .$.$) where that person knows or ought to$ know that it is inside information" (Article 8(4)).

\section{Primary and secondary insider trading}

Under international law we can identify two groups of people who may be involved in insider trading [2]. The first one is related somehow to the company in question and the second one includes other people who have acquired and used confidential information as a result of any relationship with the first group. In the consequence, the internal network and the external network can be extracted. Persons belonging to the first network are called primary insiders, while persons belonging to the second network are referred to as secondary insiders. While insider trading carried out by insiders of enterprises is studied in a few papers but insider trading carried out by all the other people practically has not been tested yet $[3,4]$. This is caused due to extremely difficult way of proving that such a crime occurred. This paper will present a simulation study to explain the impact of secondary insider trading on financial markets.

In the light of contemporary economic conditions it also seems reasonable to divide the phenomenon of insider trading into global and local terms. In global terms, this phenomenon applies to big players, such as big banks, international financial institutions, big corporations, big investment funds, influential media corporations or powerful government organizations, which generally operate in the world markets. They can achieve above-average returns during a process known as "sheep shearing" [5]. In this case, the law enforcement cannot be applied. In local terms, insider trading is small in scale and affects small players where law enforcement is possible. In this paper we deal only with insider trading in local terms.

${ }^{*}$ corresponding author 


\section{Flow of confidential information inside and outside the companies}

To create models for the use of confidential information by secondary insiders, it is necessary to outline the flow of this information in the companies themselves and outside them. The reports to be published periodically are known to those who prepared them, are responsible for their preparation and to those who have to accept them by submitting their signature. In a typical company with such matters deals the accounting department (preparing the information), the management board (being responsible for drawing up and drafting), possible management advisors (giving opinions), the top management personnel (drafting), and the supervisory board (being responsible for drawing up). Even in small stock companies it is a group of dozen to several dozen people.

When considering an inner group, it is important to pay attention to those who have access to confidential information. They can earn a living both inside and outside the company. In this context, at least two types of information should be considered:

- periodic information - financial information with a fixed period of publication and a predetermined manner of preparing them and a timetable;

- current information - information from a catalog listed in a law that has a standardized publication time.

During the investigation of the disclosure of confidential information outside the company, it is necessary first to determine the total probability of such an event. By assuming the independence of events by disclosing information and the infinite duration of disclosures, the probability can be written as follows:

$$
\begin{aligned}
& P_{\text {disclosure of confidential information }}= \\
& \quad 1-\left(1-p_{1}\right) \times\left(1-p_{2}\right) \times \ldots \times\left(1-p_{n}\right) .
\end{aligned}
$$

The symbol $p_{n}$ is the probability of a person $n$ disclosing confidential information. If $p_{n}$ is similar for each person in the inner group, then formula (1) can be simplified to

$$
P_{\text {disclosure of confidential information }}=1-(1-p)^{n},
$$

where $p$ is the probability of disclosing confidential information by an individual, and $n$ denotes the number of persons in the internal network.

Assuming $p$ at 5\% (so relatively low) and $n$ equal to 30 people, it can be calculated that the total probability of disclosure of confidential information is $78 \%$. Therefore, it is unlikely that such information will not be disclosed.

In relation to the external network, it is assumed that it consists of people who know people from the internal network. Secondary insiders verify the truthfulness of the information and, depending on the assessment, make a two-stage decision to implement or discontinue the investment. The decision to act becomes apparent as it is equivalent to a transaction using a given financial instrument. Assuming ceteris paribus that the average number of transactions is unchanged in a relatively short period of time, we should observe a short but significant increase in the number of transactions. However, the increase in the number of transactions does not necessarily imply a change in the price of a given financial instrument. Such a correlation could raise the interest of financial supervision and indicate that something unclear is happening inside the company. It must therefore be assumed that, in terms of value, transactions made by secondary insiders are not higher than the median of the annual transactions for that financial instrument. Nevertheless, such transactions should show a slightly higher value than those of earlier days.

Among the potential factors that would foresee an event that the inner group would convey important confidential information to a group of outsiders, which would simply mean disclosing it are:

A. Internal network size - the larger the internal group knowing the confidential information, the more disclosure you can expect.

B. The size of the external network - the larger the external group, the greater the chance that private investors will enter into a transaction using a particular financial instrument.

C. The relevance of information - the first appearance of a given information is more important than the subsequent reappearance. The same information can be found first in the fourth quarter report and then repeated in the annual financial report. Another example may be the information about the future dividend payment in the resolution, which will later be actually accepted confirming this information.

D. The time between the appearance of information on the internal network and its official announcement - the longer it is, the greater the probability of using this information. Thus, the secondary insiders' reaction to the information which has long closed period (annual and half-yearly reports) should be visible earlier (greater time interval back from the time of official disclosure), whereas the reaction to the information which has short closed period (quarterly report), should be visible later (smaller time interval back from the time of official disclosure).

E. Increased average transaction value on a given day compared to the average transaction on the preceding day, indicates a significantly larger number of transactions.

Two models can be formulated for such assumptions, the simulation of which allows to determine the secondary insiders' impact on financial markets. 


\section{Model of use of information \\ by secondary insiders in an infinite length of time since its acquisition}

In the first model it is assumed that secondary insiders can use confidential information at any time from the date of its acquisition. The number of persons $\left(L_{t}\right)$ who know at the time $t$ this information can then be described by the following equation:

$$
L_{t}=N_{1} N_{2}\left[1-(1-P)^{t}\right],
$$

where $N_{1}$ - number of persons inside the company who have the confidential information, $N_{2}$ - number of trusted persons from the external network connected with one person from inside the company, $P$ - the probability of passing information from the inside of a company to a trusted person outside.

Let $P_{z}$ denote the probability of transaction execution on the basis of confidential information, and $Z(t)$ - the number of transactions executed at time $t$. Based on Eq. (3) we can write the probability of the transaction execution in time $t=1$ as follows:

$$
\begin{aligned}
& Z(1)=L_{1} P_{z}= \\
& \quad N_{1} N_{2} P_{z}\left[1-(1-P)^{1}\right]=N_{1} N_{2} P_{z} P .
\end{aligned}
$$

At the moment $t=2$ we obtain the equation of the form

$$
\begin{aligned}
& Z(2)=\left(L_{2}-L_{1} P_{z}\right) P_{z}= \\
& \quad N_{1} N_{2}\left[\left(1-(1-P)^{2}\right) P_{z}-\left(1-(1-P)^{1}\right) P_{z}^{2}\right] \\
& Z(2)=N_{1} N_{2} P_{z} P\left(2-P-P_{z}\right) .
\end{aligned}
$$

The probability of transaction execution for period $t=1$ is

$$
Z(1)=L_{1} P_{z}=N_{1} N_{2} P_{z} P,
$$

so the condition for the maximum shift of this probability beyond moment $t=1, Z(2)>Z(1)$, is the following:

$$
2-P-P_{z}>1
$$

which gives

$$
P+P_{z}<1 \text {. }
$$

This means that if the sum of probabilities is greater than 1 , then the maximum will remain in period $t=1$. This is a significant result since the shift of the maximum number of transactions beyond the moment $t=1$ may indicate that the probabilities of using confidential information and its transfer is low. This applies both to each of them individually and to their sum.

For the moment $t=3$, the probability equation can be written as follows:

$$
\begin{aligned}
& Z(3)=\left(L_{3}-Z(2)-Z(1)\right) P_{z}= \\
& \quad\left[L_{3}-\left(L_{2}-L_{1} P_{z}\right) P_{z}-L_{1} P_{z}\right] P_{z} \\
& Z(3)=P_{z}\left[L_{3}-L_{2} P_{z}+\left(P_{z}-1\right) P_{z} L_{1}\right] \\
& Z(3)=N_{1} N_{2} P_{z} P\left[P^{2}+\left(P_{z}-3\right) P+\left(P_{z}^{2}-3 P_{z}+3\right)\right] .
\end{aligned}
$$

For the moment $t=4$ the equation has a form

$$
\begin{aligned}
& Z(4)=\left[L_{4}-Z(3)-Z(2)-Z(1)\right] P_{z} \\
& Z(4)=\left[L_{4}-P_{z}\left(L_{3}-L_{2} P_{z}+\left(P_{z}-1\right) P_{z} L_{1}\right)\right. \\
& \left.\quad-\left(L_{2}-L_{1} P_{z}\right) P_{z}-L_{1} P_{z}\right] P_{z} \\
& Z(4)=\left[L_{4}-P_{z} L_{3}+P_{z}\left(P_{z}-1\right) L_{2}\right. \\
& \left.\quad+P_{z}\left(P_{z}-1\right) L_{1}+\left(P_{z}-1\right) P_{z}^{2} L_{1}\right] P_{z} \\
& Z(4)=\left[L_{4}-P_{z} L_{3}+P_{z}\left(P_{z}-1\right) L_{2}\right. \\
& \left.\quad+P_{z}\left(P_{z}-1\right)\left(P_{z}+1\right) L_{1}\right] P_{z} \\
& Z(4)=N_{1} N_{2} P_{z} P\left[-P^{3}+\left(4-P_{z}\right) P^{2}+\right. \\
& \left.\quad\left(-P_{z}^{2}+4 P-6\right) P+\left(P_{z}^{3}+2 P_{z}^{2}-6 P_{z}+4\right)\right] .
\end{aligned}
$$

It follows that the analytical record of the probability of transaction execution on the basis of confidential information for subsequent periods is very complicated and it cannot be simplified. Figures $1-3$ show examples of simulations for different parameters. It follows that the probability maxima are shifted for different values in periods between $t=2$ and $t=3$.

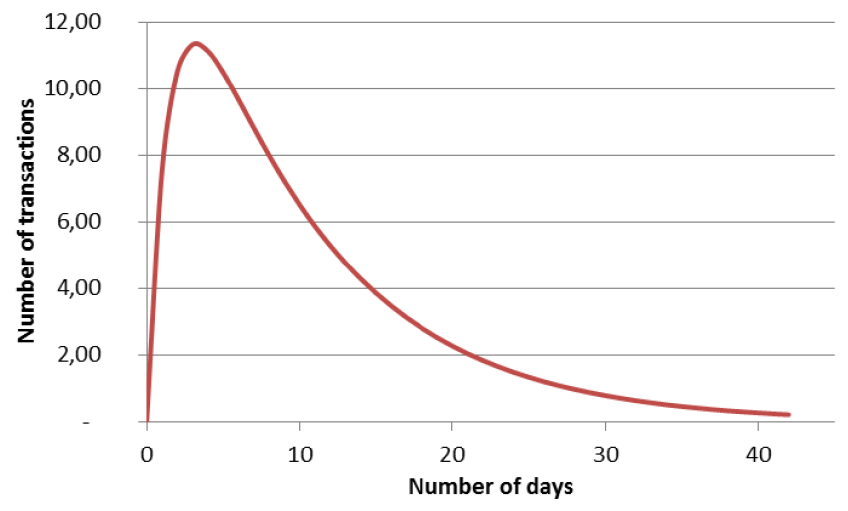

Fig. 1. $Z(t)$ for $N_{1}=30, N_{2}=5, P=10 \%$ and $P_{z}=50 \%$.

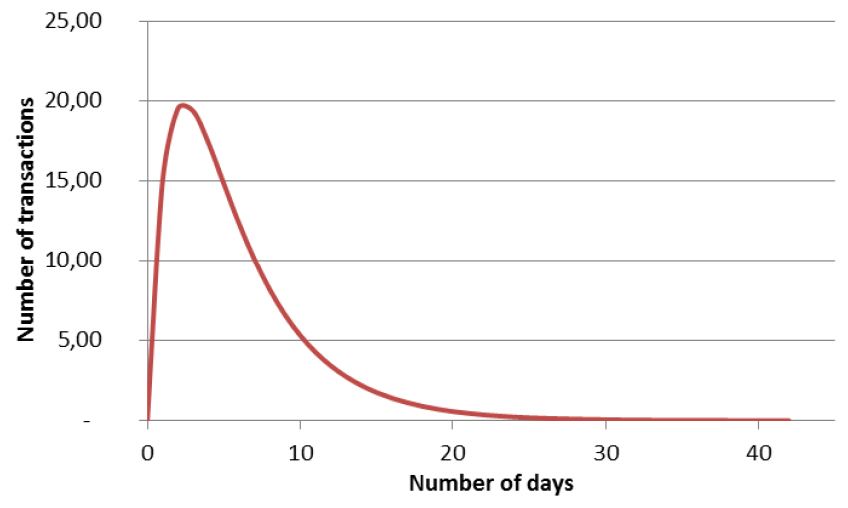

Fig. 2. $Z(t)$ for $N_{1}=30, N_{2}=5, P=20 \%$ and $P_{z}=50 \%$. 


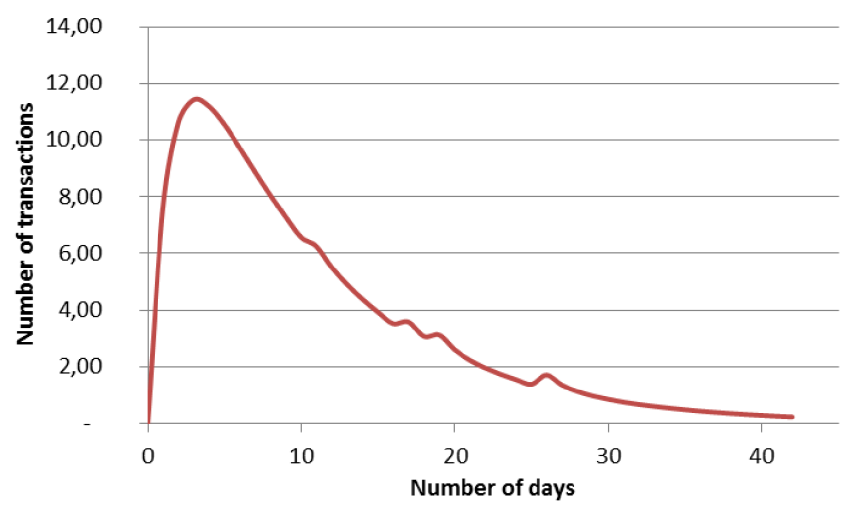

Fig. 3. $Z(t)$ for $N_{1}=30, N_{2}=5, P=10 \%$ and $P_{z}=50 \%$ after taking into account the random increase of the number of persons belonging to a trusted group (with the probability of their entry not higher than $10 \%$ ).

Analysis of the simulations presented in Figs. 1-3 allows to draw interesting conclusions. The increase in the probability of transferring confidential information from inner group to outside group from the level $P=10 \%$ to $P=20 \%$ results in a maximum increase in transactions between 11 and 20 in periods between $t=2$ and $t=3$. At the same time, the curve of the number of transactions in Fig. 2 is disappearing faster than the curve in Fig. 1. Thus, the actions taken by secondary insiders with higher probability of transmitting information are - ceteris paribus - more violent and last shorter than those with lower probability. If the number of persons belonging to the trusted group increases randomly, with the probability of their entry will not exceed $10 \%$ (Fig. 3), the result will be very similar to the one presented in Fig. 1. However, in the latter case (Fig. 3), the small peaks appear on the curve, by which its smoothness reduces. In principle, this is what you would expect.

\section{Model of use of information by secondary insiders on the day of its acquisition}

In the second model, it is assumed that the person receiving the confidential information uses it immediately on the same day, and in the following days it is no longer used. In this case, the number of persons who know the confidential information can be described by an analytical function, which greatly simplifies considerations. The number of persons $\left(L_{t}\right)$, who have the right knowledge at the moment $t$ can be described by the equation

$$
L_{t}=N_{1} N_{2}\left[1-(1-P)^{t}\right],
$$

where $N_{1}$ - number of persons inside the company who have the confidential information, $N_{2}$ - number of trusted persons who are connected with one person from inside the company, $P$ - the probability of passing information from the inside of a company to a trusted person outside.
If by $P_{z}$ we determine the probability of transaction execution on the basis of confidential information, and by $Z(t)$ the number of transactions executed at time $t$, then for the moment $t=1$ we obtain the following relation:

$Z(1)=L_{1} P_{z}=N_{1} N_{2} P_{z}\left(1-(1-P)^{1}\right)=N_{1} N_{2} P_{z} P_{z}$.

Transition to period $t=2$ requires removal of persons who have already completed the transaction. We assume that one person performs one transaction on the basis of one confidential information and that in following days after receiving the information, the transactions are not performed by that person. This leads to the equation of the form

$$
Z(2)=L_{2} P_{z}-Z(1) .
$$

Equation (6) can be transformed as follows:

$$
\begin{aligned}
& Z(2)=\left(L_{2}-L_{1}\right) P_{z}=N_{1} N_{2} P_{z}\left[\left(1-(1-P)^{2}\right)-P\right]= \\
& \quad N_{1} N_{2} P_{z} P(1-P) \\
& Z(3)=\left(L_{3}-L_{2}\right) P_{z}= \\
& \quad N_{1} N_{2} P_{z}\left[\left(1-(1-P)^{3}\right)-\left(1-(1-P)^{2}\right)\right]= \\
& N_{1} N_{2} P_{z} P(1-P)^{2} .
\end{aligned}
$$

The recurrence relation is then

$$
Z(t)=N_{1} N_{2} P_{z} P(1-P)^{t-1},
$$

which gives

$$
Z(t)=Z(1)(1-P)^{t-1} \text {. }
$$

By differentiating Eq. (7) with respect to time and looking for the zero point of derivative we obtain

$$
\begin{aligned}
& \frac{\mathrm{d} Z(t)}{\mathrm{d} t}=(t-1) N_{1} N_{2} P_{z} P(1-P)^{t-2}, \\
& 0=(t-1) N_{1} N_{2} P_{z} P(1-P)^{t-2} .
\end{aligned}
$$

It follows that for $P<1$, the function (7) reaches its maximum at $t=1$, so on the first day. The value of this maximum is

$$
Z(1)=N_{1} N_{2} P_{z} P
$$

Based on the value of the maximum number of transactions, the probability $P$ can be determined by measuring the number of transactions for a given moment, e.g. $t=n$ :

$$
P=1-\left[\frac{Z(n)}{Z(1)}\right]^{-(n-1)} .
$$

It is essential to note that the probability value $P$ may also depend on the relevance of the given information. It cannot be generalized to other cases. It should also be emphasized that the value of $N_{1} N_{2} P_{z}$ is a certain constant characteristic for a given company in the short term. In the long term, however, factors such as employment structure, business organization, or internal procedures are affected. All these factors affect the number of people in the external group. Thus, for this model, applications received from observation of one point connected 
with an increase in the number of transactions cannot be extrapolated to other points even in the same company.

Figures 4-6 show sample simulations for different parameters. As it was previously shown, the maxima of probabilities appear in the period $t=1$. In the model based on secondary insiders' information usage on a day of its acquisition, the curves of number of transactions depending on time (number of days) have a similar pattern as in the model based on secondary insiders' information

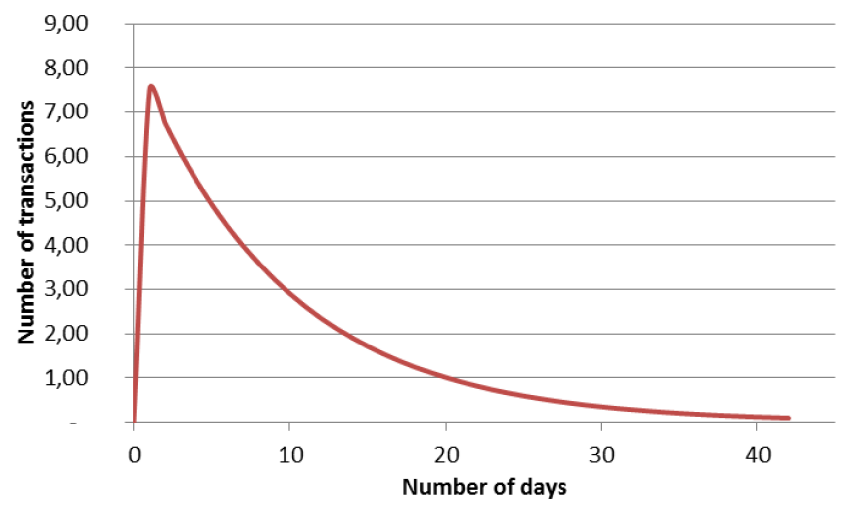

Fig. 4. $Z(t)$ for $N_{1}=30, N_{2}=5, P=10 \%$ and $P_{z}=50 \%$.

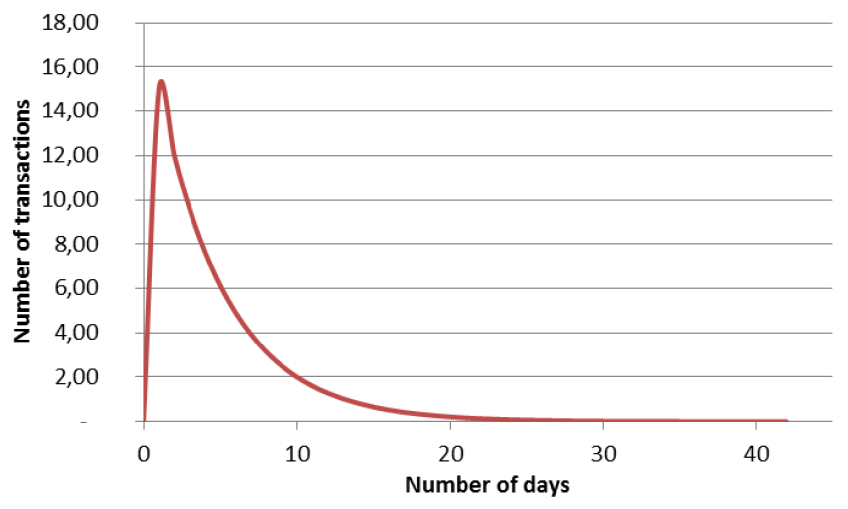

Fig. 5. $Z(t)$ for $N_{1}=30, N_{2}=5, P=20 \%$ and $P_{z}=50 \%$.

usage over an infinite long period of time of its acquisition. Figures 4 and 5 show that in the period $t=1$, the increase in the probability of transfer of the confidential information from the internal network to the external network from $P=10 \%$ to $P=20 \%$ results in a maximum increase in the number of transactions from level 7 to 15 . At the same time, the curve of transactions from Fig. 5 decreases faster in comparison with the curve from Fig. 4. Thus, secondary insiders' actions with a higher probability of transmitting information $(P=20 \%)$ are - ceteris paribus - more rapid and shorter in time than those with lower probability $(P=10 \%)$. If the number of people in the trusted group is increased randomly, where the probability of their entry will not exceed $10 \%$ (Fig. 6), the result will be very similar to this in Fig. 4. However, in the latter case (Fig. 6) just like in Fig. 3, small peaks appear on the curve, which leads to the decrease of its smoothness. It follows that both models have very similar effects on the financial markets.

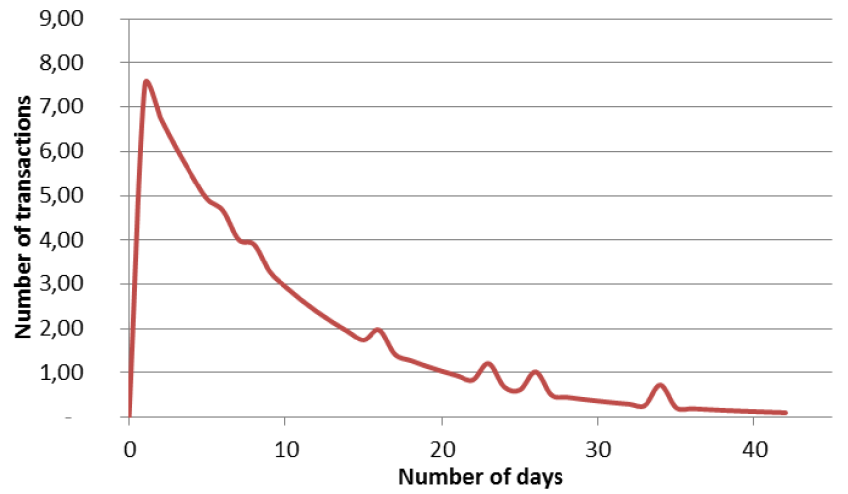

Fig. 6. $Z(t)$ for $N_{1}=30, N_{2}=5, P=10 \%$ and $P_{z}=50 \%$ after taking into account the random increase of the number of persons belonging to a trusted group (with the probability of their entry not higher than $10 \%)$

\section{Transformation of the available empirical data into parameter values}

Both models were constructed based on data obtained from 45 listed companies included in the sWIG80 index. The research covered the period from 1 January 2010 to 31 December 2014. For any company, if the available data concerned a period shorter than eighteen months, it was omitted in the research.

Data on the number of secondary insiders originating from consolidated financial statements of the examined companies for 2014. The following information was taken into account:

- "the number of persons in the management board", with regard to the entire capital group;

- "the number of persons in the supervisory board", which concerns only persons in the holding company, as very often members of the top-level management of the holding company are the members of supervisory boards of the subsidiaries, therefore one person could be counted several times;

- "the number of management advisors" if it is provided in the financial statement; otherwise it was assumed that at least one person fulfils the function of an advisor, e.g. a legal advisor;

- "the number of persons in the accounting department" if provided in the financial statement. Otherwise, it was assumed as at least 5 persons per company within the capital group, but no more than 
10 persons in total. Very frequently capital groups included 20-30 business entities, as in such cases we decided to limit the number of those persons to the minimum value; those were persons responsible for the reporting tasks of the group. If we assumed that those numbers were the total number of entities from all subsidiaries, then the number for the entire capital group would be much higher.

On the basis of these data, we found that a very narrow group of people holding confidential information, without even including the heads of business segments, can be described by the following numbers:

- minimum: 15 ,

- maximum: 71 ,

- arithmetic mean: 32 ,

- median: 29.

Therefore, in the simulations it was assumed that $N_{1}=30$.

For $N_{2}$, the value of 5 was assumed. This parameter was determined on the basis of some empirical clues. As it is known, this value cannot be confirmed by interviewing, since it would be difficult to ask the members of the management board about the number of people outside the company to whom they disclose confidential information. This parameter was determined experimentally, depending on the volume, observed in the data, of large increases in the number of transactions that preceded stock exchange reports with information considered confidential prior to such releases. This procedure was applied in previous studies involving 7 companies [6]. Carrying out the analysis of data referring to 45 companies, single significant increases in the number of transactions were observed (e.g. over a year, the average daily number of transactions concerning shares of a selected company was 7 , but one day as many as 29 transactions were recorded; moreover, this event occurred several days before publishing a report revealing confidential information). Our method applied for searching for the data concerning secondary insider trading proves effective for small and medium companies, which were subject of our studies, while their usefulness is slightly lower for large companies. This is caused by the fact that the number of secondary insiders does not grow in proportion to the company size. Since the average number of transactions in shares of large companies is high, this provides an opportunity for secondary insiders to better hide their illegal activity.

As regards determination of the $P$ parameter value, it is not constant even for a specified company, as it depends on the quality of information. Of course, it is possible to quantify the importance of information, but it is not necessary, as this parameter affects only the speed at which the increased number of transactions disappears.
Due to the fact that the "second day effect", i.e. an increased number of transactions on the day following the maximum number of transactions, was not observed in the stock exchange data, we did not decide to undertake more detailed studies and confined ourselves to establishing $N_{1}, N_{2}$, and $P_{z}$ parameters.

Regardless of the type of model, the maximum value of the function depends only on the product of $N_{1} N_{2} P_{z}$. Therefore, it is of no significance whether we consider the "short" memory model (well-known from behavioural theories, where a secondary insider invests immediately after obtaining confidential information or does not invest at all; therefore the maximum activity falls on the day of obtaining the information), or we consider the "long" memory model (when the maximum falls between day 2 and 3 after obtaining the information). In both cases, the value of the first parameter $\left(N_{1}\right)$ was determined from available data based on the arithmetic mean, while the value of the second $\left(N_{2}\right)$ and the third parameter $\left(P_{z}\right)$ resulted from the observed effects in stock exchange quotations. This means that the values of the parameters were chosen on a representative basis.

Apart from the empirical support for the reliability of simulation results described above, we also applied theoretical support. This consists in explaining the simulation based on existing and well-proven market performance theories: the efficient market hypothesis, the fractal market hypothesis, and the coherent market hypothesis. It appears that the simulations are most compatible with the last two hypotheses, which makes the results of our studies even more reliable.

\section{Secondary insider trading in different models of the functioning of financial markets}

\subsection{The efficient market hypothesis}

At the root of the efficient market hypothesis (EMH) lies informational efficiency. Markets can only be effective in relation to a certain set of information, which means that there is no movement in the prices of financial instruments following the disclosure of this information to all investors. So profit is not possible if investment decisions are made on the basis of this information. From this point of view, there are three forms of efficient market hypothesis: weak, semi-strong, and strong. In the weak form in instrument prices all historical information is included. In the semi-strong form prices include all public information (including historical information), while in the strong form prices include all information, both public and non-public [7].

In this context, we can make a first assessment of the impact of both the above-mentioned ways of using confidential information on financial markets. This obviously depends on what form of market efficiency will be adopted. In the strong form an investor cannot achieve above-average returns even if he/she has confidential information. This would only be possible in the conditions 
of semi-strong and weak efficiency. Some studies suggest that insider trading carried out by private insiders can increase the efficiency of the market and accelerate the change of the share price to reflect the confidential information [8-10]. Other studies prove something opposite [11-13]. However, before any conclusions could be drawn regarding the impact on market efficiency, the speed of the flow of confidential information should be taken into account.

In all definitions of efficient market hypothesis, it is assumed that new information is reflected by prices rapidly, almost immediately, and fairly accurately [14]. The simulations shown in Figs. 1-6 deny this view, as they show that the use of confidential information can last a relatively long time, from 15 to 30 days. This is logical, because secondary insiders may use confidential information until it is disclosed in one way or another. In addition, under this concept, the small peaks shown in Fig. 3 and 6 remain unexplained. Thus, the secondary insider trading phenomenon is not fully explained within EMH and therefore it is impossible to accurately determine its impact on the market.

\subsection{The fractal market hypothesis}

In the fractal market hypothesis (FMH), the impact of information on the price of financial instruments depends on the time horizons accepted by the investors. There are many market participants and each one may have a different time horizon of investing. Investors with short-term horizons typically use technical analysis, while investors with long-time horizons typically use fundamental analysis. Prices result from a combination of technical indicators and long-term fundamental valuation. Therefore, they do not immediately reflect any available information [15]. According to FMH, the market moves in the area defined by the stage of stability and the stage of instability. If the fundamental information is reduced in the market, the investors' varied horizons will shrink to a uniform level and there will be move into the phase of instability. This is equivalent to a butterfly effect, so chaotic dynamics will dominate the market [16].

The simulation results of the use of confidential information are consistent with FMH predictions. The influence of confidential information on investors' time horizons is very important. If their disclosure does not change these horizons, insider trading will not affect market stability. Otherwise, the disclosure shrinks the investor's horizons to a similar level and will accelerate the appearance of a chaotic phase [17]. In addition, within FMH, the inequalities in the curves of Figs. 3 and 6 can be interpreted as stirring of fractals. This hypothesis is also consistent with the period of usage of confidential information in secondary insider trading.

\subsection{The coherent market hypothesis}

The coherent market hypothesis $(\mathrm{CMH})$ is the most econophysical of the proposals for functioning of the financial markets discussed here. It is based on the Ising model, which describes the behaviour of particles in the magnetized bar of iron, and the theory of social imitation [18]. According to $\mathrm{CMH}$, financial markets can go through four basic phases:

1. Random walk meaning market efficiency,

2. Unstable transition - the lack of efficiency caused by trends that persist until the emergence of new public information,

3. Coherent market, where material fundamental information affects herd behaviour, which may take the form of a bull market or a bear market.

4. Chaotic market - butterfly effect.

The simulation results provided by both models of use of confidential information can be best explained within CMH. The effects of actions taken by secondary insider traders have the biggest impact on markets when they are in the second or fourth phase. In these phases insider traders either accelerate the appearance of unstable transition or increase the complexity of the markets. In the case of a random walk we deal with EMH, and the role of insider trading in such markets has been explained earlier. Significant impact of disclosure of confidential information on the market in the coherent phase is highly unlikely. In addition, the unevenness in the distribution curves of number of transactions shown in Figs. 3 and 6 may signal the beginning of chaotic dynamics.

\section{Conclusions}

The results of simulation of two models of the use of confidential information, within an infinite long period of time from its receipt and on the day of its flow to the external network, was considered within three concepts of financial markets functioning: $\mathrm{EMH}, \mathrm{FMH}$, and CMH. According to both models insider traders may affect the financial markets and their effectiveness, but only in the weak and semi-strong EMH versions. From a strong EMH standpoint they are neutral. Models do not fully confirm the basic assumption of each version of EMH, with immediate or rapid reflection of the information on prices. Making transactions in the long term, from 15 to 30 days, may indicate that secondary insiders get aboveaverage returns with relatively low risk growth.

The impact of confidential information on financial markets can be fully analyzed within $\mathrm{CMH}$, as this concept incorporates both EMH and FMH. The biggest effects of insider trading can occur in the phases of unstable and chaotic transition. In the latter case, the markets are extremely sensitive on initial conditions and even revealing insignificant confidential information or rumour, literally the flutter of a butterfly's wings, can fundamentally change their dynamics. This means that even the absolutely imperceptible change can be significant here. Theoretically, a change in price is considered unimportant if it is lower than the smallest monetary unit in 
which the currency is determined. Under Polish conditions, absolutely imperceptible change means that the price fluctuation is less than one grosz.

Irregularities in the distribution of transactions (Figs. 3 and 6) can be best explained by the use of nonlinear dynamics, i.e. within FMH and CMH. They can herald a fractal distribution of a number of transactions, an unstable transition in the market, or the beginning of the chaotic dynamics. Confirmation of these hypotheses, however, requires further research.

In most countries, legal regulations aim to eliminate primary and secondary insider trading. At the same time, in the contemporary world, there is a rapid development of electronic and direct surveillance methods, which makes it increasingly difficult to keep in secret the transmission of confidential information [19]. As a result of rapid technological advances, surveillance and espionage equipment are getting better and cheaper. Organizations with this type of business, having the most common three-letter abbreviations, are faced with declining costs. This means that the risk of local insider trading is likely to continue to increase, indicating a gradual decline in this phenomenon in the future.

\section{References}

[1] Regulation (EU) No 596/2014 of the European Parliament and of the Council of 16 April 2014 on market abuse (market abuse regulation) and repealing Directive 2003/6/EC of the European Parliament and of the Council and Commission Directives $2003 / 124 / E C, 2003 / 125 / E C$, and 2004/72/EC, Official Journal of the European Union, L 173.

[2] J.H. Thompson, Int. J. Account. Financ. Report. 3, 1 (2013).

[3] V.V. Acharya, T.C. Johnson, J. Financ. Econ. 84, 110 (2007).
[4] V. Ivashina, Z. Sun, Institutional Stock Trading on Loan Market Information, AFA 2008 New Orleans Meetings Paper, 2010.

[5] S. Hongbing, The Currency War: The Real Sources of Financial Crises, Wydawnictwo Wektory, Bielany Wrocławskie 2010 (in Polish).

[6] A. Jakimowicz, A. Baklarz, Acta Phys. Pol. A $\mathbf{1 2 9}$ 980 (2016).

[7] E.F. Fama, J. Finance 25, 383 (1970).

[8] H.G. Manne, Insider Trading and the Stock Market, The Free Press, New York 1966.

[9] H.G. Manne, Harvard Busin. Rev. 44, 113 (1966).

[10] H.G. Manne, Challenge 15, 14 (1967).

[11] J.-J. Laffont, E.S. Maskin, J. Politic. Econ. 98, 70 (1990).

[12] S. Roddenberry, F. Bacon, J. Finance Accountancy 8, 1 (2011).

[13] I. Antoniadis, C. Gkasis, A. Sormas, Proc. Econ. Finance 24, 60 (2015).

[14] B.G. Malkiel, J. Econ. Perspect. 17, 59 (2003).

[15] E.E. Peters, Fractal Market Analysis. Applying Chaos Theory to Investment and Economics, Wiley, New York 1994

[16] E.N. Lorenz, The Essence of Chaos, UCL Press, London 1995.

[17] A. Jakimowicz, Foundations of State Interventionism: Philosophy of Economics History, Wydawnictwo Naukowe PWN, Warszawa 2012 (in Polish).

[18] T. Vaga, Profiting from Chaos. Using Chaos Theory for Market Timing, Stock Selection, and Option Valuation, McGraw-Hill, New York 1994.

[19] K. Malinowski (Lorak), Electronic and Direct Surveillance, so How to Get Anything, for Anyone, in any Way, Part 2, SpyShop Expert - Inwigilacyjne Wsparcie Operacyjne, Warszawa 2017 (in Polish). 